\title{
Os Indígenas Através da Leitura: possibilidades de narrativas sobre $O$ indígena em "Através do Brasil", de Olavo Bilac e Manoel Bomfim
}

\author{
Helena Azevedo Paulo de Almeida*
}

helenoca@gmail.com

\begin{abstract}
Resumo
No decorrer do século XIX, ocorreu uma acirrada discussão sobre o lugar do índio na constituição da sociedade brasileira. Podemos destacar duas vertentes principais de abordagem: a Romântica e outra vertente, à figura de Varnhagen. Assim, o presente trabalho tem por intenção discutir as modificações e permanências desses discursos, a partir de uma análise do livro de leitura "Através do Brasil", escrito por Olavo Bilac e Manoel Bomfim, publicado pela primeira vez em 1910. Os livros de leituras, materiais escolares utilizados no período republicano estipulado, foram de grande importância para a construção de uma determinada memória sobre os indígenas brasileiros, principalmente a partir da noção de memória coletiva.
\end{abstract}

\section{Palavras-chave}

Material escolar; Primeira República Brasileira; Indígenas

Indian People Through Reading: narrative possibilities about indian people in "Através do Brasil", by Olavo Bilac and Manoel Bomfim**

\begin{abstract}
During the 19th century a ferocious debate took place in Brazil, about the place of the American Indian in Brazilian society. Two tendencies can be emphasized: the Romantic and another one, linked to Adolfo de Varnhagen. Thus, the present paper in tends to discuss the modifications and persistence of these discourses, based on the reading book (livro de leitura) analysis of "Através do Brasil", written by Olavo Bilac e Manoel Bomfim, published for the first time in 1910. The reading books, a kind of school material which was used in the republican period, were important to create a public memory about Brazilian indians, especially referring to a collective memory notion.
\end{abstract}

\section{Keywords}

School material; Brazilian First Republic; Indians

\footnotetext{
*Universidade Federal de Ouro Preto.

**Agradeço ao orientador Prof. Dr. Marcelo de Mello Rangel, ao co-orientador Prof. Dr. Marcelo Santos de Abreu e ao Grupo de Pesquisa em História, Ética e Política, da Universidade Federal de Ouro Preto (GHEP-UFOP) pela leitura atenta e comentários.
} 
No período imperial, as interpretações e imagens referentes aos indígenas eram muito variadas, assim como seu lugar na construção de uma identidade nacional. Dentre as vertentes, creditamos a duas delas grande centralidade no que tange à tematização do indígena ao longo do século XIX, a saber: a Romântica, exemplificada aqui por Gonçalves de Magalhães, que exaltava o indígena em sua participação nas narrativas históricas e literárias, e outra ligada a Francisco Adolfo de Varnhagen, que reconhecia a existência do indígena na história brasileira, mas não creditava maior importância à existência dos grupos étnicos, colocando esses personagens sob uma perspectiva de subrepresentação e, no máximo, como possibilidade de ser mão de obra rural forçada, de forma a cogitar a possibilidade de que os indígenas substituíssem a mão de obra escrava negra.

O IHGB e os Românticos, portanto, são marcos referenciais para a construção da identidade nacional, principalmente considerando o final do século XIX e o início do século XX. A produção intelectual, embora de grande importância, não era facilmente divulgada. Seu público era restrito, e isso devido ao alcance das publicações e à esparsa demografia alfabetizada. Assim, é por meio de certa perspectiva da história pública, a qual se dedica à relação entre memória e narrativa, que trataremos de certos livros escolares publicados durante a primeira década do século $\mathrm{XX}^{1}$.

É importante apontar a permanência da perspectiva, desenvolvida principalmente no IHGB, da utilização de mão de obra indígena nos trabalhos agrícolas. O SPILTN (Serviço de Proteção ao Índio e Localização de Trabalhadores Nacionais, criado a partir do Decreto $n^{\circ} 8.072$, de junho de 1910) era pensado também a partir de uma perspectiva unívoca em relação aos indígenas, já que dentre os objetivos principais estava a intenção de agrupamento de diferentes etnias em um mesmo território, ou seja, aldeamentos modernos, baseados nos aldeamentos coloniais. Dessa forma, o destino desses grupos, perante a ótica do SPILTN era ser assimilado à categoria de trabalhadores rurais, possibilidade muito próxima à apresentada por Varnhagen em seu "Memorial”, publicado em 1849.

O contexto agitado das primeiras décadas do século XX gerou impacto direto no âmbito educacional, considerando que os materiais escolares deveriam ser aprovados previamente pelo governo. Muitos deles apresentavam a aprovação do governo em destaque nas folhas de rosto, “Aprovada pelo Governo e adoptada pela diretoria Geral da Instrução Publica para as Escolas e Grupos Escolares do Estado de Minas Gerais", ressaltando assim a relação direta da produção didática com a legislação vigente nos programas de ensino (FRADE; MACIEL, 2006). A indagação nos remete à construção das representações sobre os indígenas, que faziam parte marcante das discussões intelectuais e sociais do período, e também dentro do espaço escolar. Assim, os livros de leitura, material escolar analisados neste trabalho, não eram pensados diretamente para áreas específicas, mas sim como um ponto de convergência de conhecimentos disciplinares múltiplos.

Com o advento da República, o Estado conferiu uma importância crucial à utilização desse material, principalmente a partir de 1908, momento em que "a comissão responsável por rever a lista de obras adotadas em escolas públicas paulistas chegou a recomendar que os alunos só se utilizassem dos livros de leitura, bastando para as demais disciplinas as explicações dos

${ }^{1}$ Para a conceitualização de "história pública", utiliza-se aqui a abordagem realizada por Juniele de Almeida e Marta Rovai, sobre a prática do uso da história em locus público, além da divulgação por conhecimento organizado e sistematizado pela ciência, pressupondo porém uma pluralidade de disciplinas. Para leitura mais detida, consultar ALMEIDA; ROVAI, 2011. 
mestres" (PINHEIRO; MOREIRA, 2011, p. 3). Assim, os livros de leitura, como "Através do Brasil", foram utilizados muitas vezes, principalmente em escolas do interior, como única fonte física de utilização de material escolar. Mas, como as perspectivas sobre os indígenas, construídas durante o período Imperial se encontravam agora, na República?

Varnhagen não era popular entre seus pares no IHGB, assim como sua escrita também não era para qualquer leitor. A poesia de Gonçalves de Magalhães também não era própria à grande circulação entre as massas do povo brasileiro ${ }^{2}$, embora ele não deixasse de figurar nas preocupações do poeta. A querela entre as duas figuras ressalta a importância de ambas as abordagens: além da dicotomia Tupi versus Tapuia, a positivação ou a negativação/silenciamento do indígena na história brasileira.

O binômio bárbaro/civilizado e, ainda, Tupi/ Tapuia, permanecia, isso em razão do objetivo que é o da constituição de unidade nacional a partir do elemento branco, europeu. A ideia de degeneração para tematizar a personagem indígena era muitíssimo presente, a partir, também, de Varnhagen, assim como a valorização do indígena antepassado em contraposição ao autóctone presente, como demonstra Magalhães. Assim,

o resultante diálogo entre o pensamento científico e a política indigenista produziu, ao longo do século XIX e, de certo modo, do XX, imagens e opiniões conflitantes, ora promovendo a inclusão das populações indígenas no projeto de nação, ora sancionando a sua exclusão (MONTEIRO, 2001, p. 133).
Como a oscilação sobre a perspectiva do tema indígena foi constante no século XIX, nesse sentido podemos perceber algo semelhante na Primeira República: oscilações, que chamamos aqui de tensão, ora positivando os indígenas, ora negativando-os, ou silenciando-os. A "História Geral do Brasil" de Varnhagen engessou uma determinada mentalidade sobre o indígena e "praticamente consolidou o abismo que iria prevalecer nos estudos sobre as populações indígenas até um período bem recente, circunscrevendo os índios a uma distante e nebulosa pré-história ou ao domínio exclusivo da antropologia" (MONTEIRO, 2001, p. 37).

\section{Sobre os livros de leitura}

É importante ressaltar que as obras, tanto de Gonçalves de Magalhães quanto de Varnhagen tinham limites de difusão e suas propostas, assim como de seus contemporâneos e seus precedentes, foram amplamente divulgadas, principalmente por meio de materiais didáticos. A análise de tais materiais permite reconstruir parte do projeto nacional e "civilizador" vinculado à educação, mesmo que seja ainda uma síntese inicial e incompleta do ensino de história e sua importância, tanto no período Imperial quanto na Primeira República.

O livro de leitura deve ser encarado sob uma ótica específica: como muitos materiais didáticos, este também têm caráter excludente. Como já mencionado, os livros de leitura foram indicados como principal e, muitas vezes, único recurso didático do professor, vinculando e divulgando informações que foram carregadas por milhares de crianças e jovens durante suas vidas.

\footnotetext{
${ }^{2}$ Deve-se considerar ainda que a "Confederação dos Tamoios", teve pouca repercussão assim como poucas edições publicadas, até a Primeira República, como aponta Ivan Cavalcanti Proença na "Introdução Literária” da edição de "Confederação dos Tamoios", publicada em 1994. É a partir das poucas publicações do poema que podemos considerar a pouca divulgação do que podemos chamar de seu "projeto indígena".
} 
Uma característica importante dos livros de leitura era que tais materiais apresentavam a convergência de variadas informações. Essa é uma característica que despertava interesse, não apenas em alunos, mas também em seus pais. Assim, pode-se inferir que, por exemplo,

os manuais didáticos (...), elaborados por profissionais que, por formação, revelavam-se pouco aptos para articulá-los às suas especializadas destinações pedagógicas, eram livros que disputavam, ainda, o emprego em outros niveis de ensino e numa fatia do mercado que ia além da reduzida clientela escolar (ALVES, 2009, p. 21).

É importante ressaltar a significativa ampliação do próprio espaço escolar e desta "clientela", afinal, durante a Primeira República, "houve o crescimento e fortalecimento das escolas primárias e o surgimento das escolas mistas, que propiciaram a construção de um novo sistema escolar (...), exigindo a presença do livro como suporte didático no contexto escolar" (PINHEIRO; MOREIRA, 2011, p. 2). Assim, os livros de leitura atingiam uma camada maior da população. É importante pensar também que

não podemos ignorar os livros de leitura, escritos pelos pioneiros, e que foram, no Brasil, a primeira manifestação consciente da produção de leitura especifica para crianças. Em última análise, tais livros foram também a primeira tentativa de realização de uma literatura infantil brasileira, mostrando que os conceitos de 'literatura' $e$ 'educação', andaram sempre essencialmente ligados (COELHO, in HANSEN, 2010, p. 38.).

Utilizados no aprendizado da língua portuguesa, "assunto moral e cívico, história regional, aprovação e adoção pelas autoridades estaduais de educação" (HANSEN, 2010, p. 44), os livros de leitura eram usados nas escolas primárias e secundárias de todo o país. Escritos para atrair o leitor, seja o aluno ou mesmo os seus pais, a maior parte desse material se baseava em uma redação ficcional e fluida. Muitos foram inspirados em clássicos europeus como o livro "Cuore", de Edmundo de Amicis, publicado pela primeira vez no Brasil pela Editora Francisco Alves, em 1891. A longevidade das edições desses livros explica sua presença em várias regiões (e gerações) do país, caracterizando a grande difusão de seu conteúdo.

É importante ressaltar a capacidade de sensibilização que os livros de leitura tiveram na vida de várias gerações, e isso a partir do que se pode chamar de relacionamento afetivo aluno/texto (LAJOLO, 1982, p. 25),o que demonstra a importância das obras tanto no âmbito escolar quanto em suas vidas pessoais.

Devemos considerar que, durante a transição do século XIX para o XX a educação "moral, cívica e religiosa (...) tornou-se o eixo das preocupações para os que almejavam o perene controle das relações e das estruturas sociais, como forma capaz de regenerar o País" (BASTOS, 2012, p. 3). Assim, é durante as primeiras décadas da Primeira República que "o fortalecimento da escola (...) e as campanhas cívicas em prol da modernização da imagem do País favoreceram o desenvolvimento da literatura infantil brasileira e o seu lastro ideologicamente conservador"(BASTOS, 2004, p. 4).

\section{O livro de leitura "Através do Brasil", de Olavo Bilac e Manoel Bomfim}

As primeiras décadas do século $\mathrm{XX}$ apresentaram grandes mudanças para a população brasileira, como já mencionado. Encontramos a primeira década de 1900 em um clima de forte nacionalismo que, por sua vez, se diferenciava do patriotismo nascente do século XIX. Se, em um passado recente, o indígena era tido como ideal, heróico 
para os Românticos, seu lugar não estava claro na República.

Os autores Olavo Bilac e Manoel Bomfim são figuras notórias no período estudado, tanto no que tange às políticas públicas quanto ao ambiente escolar propriamente dito. Olavo Bilac, carioca, aos 15 anos já havia entrado na Faculdade de Medicina do Rio de Janeiro. As letras, porém, o envolvem desiludindo-o de seu curso, o qual não concluiu. Além de direcionar sua atuação profisssional diretamente à escola, o autor é um dos principais defensores do serviço militar obrigatório, o que é fator elucidativo do nacionalismo o qual defendia. Bilac é responsável pela publicação de inúmeras obras direcionadas ao público infantil. Em 1904, sua obra "Poesias Infantis" foi premiada pelo Conselho Superior de Instrução Pública do Rio de Janeiro e editada até 1961, demonstrando assim sua longevidade (CORDEIRO, 2005).

Assim como Bilac, Manoel Bomfim também cursou a Faculdade de Medicina do Rio de Janeiro, embora tenha concluído o curso em 1890. Após a morte da filha, Bomfim abandonou a medicina e passou a se dedicar ao ensino ${ }^{3}$. Suas preocupações quanto à sociedade brasileira e como essa era vista são demonstradas nas publicações de ensaios como "O Brasil na História", publicado pela primeira vez em 1930. Assim, é possível perceber que tanto para Bilac quanto para Bomfim,

um projeto político não poderia ter sucesso se não estivesse solidamente apoiado em uma cultura ético-moral minimamente estabelecida e generalizada. Portanto, um programa para alfabetização e educação fazia-se urgente para orientar a população à proposta política moderna de nação (Grifo nosso. FERREIRA, 2016, p. 12).
A orientação da população a partir de um programa educacional conjugada com a influência do material escolar na construção da memória individual acompanha uma

impressão [que] pode apoiar-se não somente sobre a nossa lembrança, mas também sobre as dos outros. Nossa confiança na exatidão de nossa evocação será maior, como se uma mesma experiência fosse recomeçada, não somente pela mesma pessoa, mas por várias (HALBWACHS, 1990, p. 24).

Publicado pela primeira vez em 1910, “Através do Brasil" inicia com a apresentação do capítulo "Advertência e Explicação", que funciona como uma espécie de instrução ou manual para leitura. Este capítulo foi claramente direcionado aos professores e, principalmente, aos pais como mediadores da leitura infantil. Podemos encarar tal teor como uma orientação da leitura que explica o porquê do conteúdo do livro. Assim, os autores ressaltam primeiramente que realizaram a escrita de tal livro...

para o curso médio das Escolas
Primárias do Brasil, a fim de ser ele o
único livro destinado às classes desse
curso; tal é, de fato a indicação
pedgógica aconselhada hoje: às
primeiras classes do ensino primário não
deve ser dado outro livro além do livro
de leitura (BOMFIM; BILAC, 1925, p.
V).

Tal passagem enfatiza a importância da utilização do livro de leitura como único material escolar tanto nas escolas primárias das capitais quanto no interior do país. Vale ressaltar que os autores tentam criar uma determinada "primeira imprensão" em seus leitores a partir do direcionamento da leitura, fornecendo "instruções claras sobre as possibilidades

\footnotetext{
${ }^{3}$ Manoel Bomfim, após concluir o magistério, passou a lecionar Educação Moral e Cívica na Escola Normal do Rio de Janeiro. Para leitura detida, consultar AGUIAR, 2005.
} 
que eles previam para o melhor uso daquele livro" (HANSEN, 2010, p. 25). Para os autores, o melhor uso para o livro de leitura era diferenciá-lo da escrita das enciclopédias, com poucos atrativos à faixa etária. O livro se desenvolve a partir de uma estrutura narrativa atraente à infância, de forma que Bomfim e Bilac destacam a importância de cativar o leitor, diferentemente da escrita enfadonha do molde enciclopédico: "esse erro se tem repetido em diversas produções destinadas ao ensino e constituídas por verdadeiros amontoados didáticos, sem unidade e sem nexo, através de cujas páginas insípidas se desorienta e perde a inteligência da criança" (BOMFIM; BILAC, 1925, p. VI).

Assim, os autores buscam promover a afeição do leitor pelo livro, de forma que o aluno se identifique com os personagens da narrativa. Estabelecer a afetividade com o aluno mesmo que por meio de material escolar, "contribui para ampliar e assegurar a realização da construção do conhecimento durante o processo de ensino/aprendizagem" (PEREIRA, 2010, p. 17). Bilac e Bomfim ainda frisam que

não se pode influir eficazmente sobre o espirito da criança e captar-lhe a atenção, sem lhe falar ao sentimento. Foi por isso que demos ao nosso livro (...) um tom dramático - para despertar o interesse do aluno e conquistar-lhe o coração. A Vida é ação, é movimento, é drama. Não devíamos apresentar o Brasil aos nossos pequenos leitores, mostrando-lhes aspectos imotos, apagados, mortos (BOMFIM; BILAC, 1925, p. VIII).

Como destacado, Bilac e Bomfim não tinham intenção de apresentar um Brasil "imoto, apagado e morto". Talvez por isso os indígenas tenham uma presença tão escassa, insuficiente até para representálos como parte do corpo nacional, o que podemos encarar mais como um silenciamento dos indígenas brasileiros do que como negativação. É importante ressaltar que, no decorrer do texto, prevalece uma tensão entre esse silenciamento e a positivação do indígena, de modo que, se alguma característica negativa é ressaltada, os autores tratam de contrapor quase que imediatamente certa positividade.

Os índios em "Através”, como veremos, passam uma sensação de número reduzido ou mesmo uma etapa a ser superada. Como demonstra a última citação, os autores propõem que a orientação de leitura para a criança parta do princípio de uma grande lição a ser tirada desta afetividade, uma lição patriótica, já que desde o século anterior era fundamental...

\begin{abstract}
uma história da pátria brasileira na qual os fatos regionais, tidos por significativos e importantes, se tornassem elementos que pudessem ser entendidos como gerais para a compreensão da história geral, vista como unitária, ligando o país à civilização, ao definir a formação da Nação pela historiografia que criava (BANDEIRA DE MELO, 2008, p. 38).
\end{abstract}

Assim, para Bilac e Bomfim, "Através" trazia "uma visão, a um tempo geral e concreta da vida brasileira" (BOMFIM; BILAC, 1925, p. VII). Essa visão "concreta" reforça outra proposta primordial dos autores: a veracidade das informações que o livro continha. É necessário reforçar que o...

olhar intelectual, na Primeira República, foi conduzido pelo fio de conceitos tais como civilização, progresso, raça e evolução, compondo o periodo da Bélle Époque e da propagação da literatura de cunho realista. Evidenciou-se nesse periodo o entrelaçar do social com o cultural na preocupação da formação de uma literatura nacional, capaz de solidificar a composição de uma nacionalidade brasileira (Grifo nosso. CASTILHO, 2005, p. 2).

A elaboração de uma literatura com tal "cunho realista" direcionada às crianças reforça a veracidade 
que as informações contidas na obra teriam de acordo com os autores, mas principalmente aos olhos dos mediadores da leitura: professores e pais. Assim, é por meio disto que seria a "realidade" factual esteticamente organizada e apresentada - que os autores propõem um determinado espaço (ou não) para os indígenas no Brasil, na história do Brasil e na República.

A primeira aparição do termo índio se dá ainda em "Advertência e Explicação". Neste momento, os autores apontam, sem muitas delongas, para as condições em que o Brasil se encontraria antes da colonização. Seria nesse momento "pré-civilizatório", a partir de uma determinada imagem que o Brasil construía de si mesmo, que os indígenas seriam encontrados, em "um sertão bruto, onde havia...índios..." (BOMFIM; BILAC, 1925, p. X). O indígena então é apresentado a partir de um contraste nítido entre selvageria - o "sertão bruto" - e industrialização, ou seja, o período de modernização que o país se encontrava. Assim, a proposta a ser trabalhada era a de que o contato entre os habitantes do território brasileiro era benéfico, muito próprio daquele período após a defesa da miscigenação, desenvolvida também por Von Martius, no século XIX.

A oposição entre "civilização" e "selvageria", ou ainda entre o Eu e o Outro, mais uma vez toma força. É necessário acentuar que...

este movimento envolvendo a circulação e a reapropriação de ideias e imagens em momentos muito distintos também marcou a trajetória de um padrão bipolar que condicionou as maneiras de perceber $e$ interpretar o passado indigena (...). Inscrito inicialmente no binômio Tapuia/Tupi, este padrão foi reciclado em várias conjunturas distintas, reaparecendo em outros pares de oposição, tais como bravio/manso, bárbaro/policiado ou selvagem/ civilizado. Mas essas percepções e interpretações não ficaram apenas nas divagações historiográficas ou nos debates antropológicos em torno da unidade e diversidade dos indios, pois tiveram um impacto profundo sobre a formulação de políticas que afetaram diretamente diferentes populações indigenas (MONTEIRO, 2001, p. 10).

Tal "impacto profundo" pode ser visto claramente em decorrência das publicações didáticas, e isso durante toda a primeira metade do século XX. Ainda, a palavra dos autores demonstra a busca por uma compreensão do índio em seu papel e lugar précabralino, o que demonstra mais uma tentativa de compreensão do indígena a partir de sua própria historicidade, mais próxima às tentativas empreendidas por Magalhães e os Românticos do século XIX, do que de negativação dos grupos étnicos, proposta por Varnhagen; claro, a partir do binômio que é o da civilização versus selvageria. Essa tentativa de compreender os autóctones é apresentada de forma a instruir o professor:

$$
\begin{aligned}
& \text { E então o professor apelará para a } \\
& \text { observação da criança, para que ela note a } \\
& \text { diferença entre o estado selvagem e as } \\
& \text { indústrias, instituições, obras e costumes que } \\
& \text { distinguem a civilização; mostrará que essas } \\
& \text { instituições e indústrias faltam ainda em } \\
& \text { grande parte a algumas terras do interior, } \\
& \text { onde a civilização ainda não penetrou. Esta } \\
& \text { lição, desenvolvida de forma acessível à } \\
& \text { mentalidade do aluno, e apelando sempre } \\
& \text { para seu próprio raciocínio e para a sua } \\
& \text { própria observação, há de leva-lo facilmente } \\
& \text { a fazer uma ideia do que era o Brasil } \\
& \text { selvagem (Grifo nosso. BOMFIM; BILAC, } \\
& \text { 1925, p. X). }
\end{aligned}
$$

Vemos assim, mais uma vez, o binômio selvagem/civilização sendo utilizado pelos autores para evidenciar o processo de "civilização progressiva" que eles defendiam. Essa passagem também é significativa na tentativa de provocar o aluno e, nesse caso, principalmente o professor, a uma proposta de "presentificação" (GUMBRECHT, 2010) do passado (no caso das lições de história), por meio da adequação 
ao cotidiano do aluno. Este cotidiano do aluno deve ser encarado como uma estratégia de aproximação do conteúdo do livro aos interesses e curiosidades do aluno, isso a partir de envolvimento do jovem por meio de uma narrativa que sensibilizava o leitor, que poderia fazê-lo imaginar que as aventuras dos personagens poderiam ser experienciadas pelos estudantes, cativando-os de forma a instigá-los a não só entender o país como nação, por meios desta espécie de relato de viagem, mas a sentir-se parte dessa nacionalidade. O aluno é assim introduzido no mundo nacional, de maneira que...

(...) o valor estético estaria invariavelmente na capacidade de transportar uma mensagem ética; e que, por isso, dependendo em larga medida das perspectivas éticas desses artefatos, o valor estético-ético relativo de qualquer texto ou obra de arte que estivéssemos ensinando nos daria uma base de orientação pedagógica (GUMBRECHT, 2010, p. 122).

O papel do professor é o de ser o mediador da leitura, visto que, para os autores, é o professor que detém o conhecimento a ser ensinado:

(...) a verdadeira enciclopédia do aluno nas classes elementares é o profesor. É ele quem ensina, é ele quem principalmente deve levar a criança a aprender por si mesma, isto é: a por em contribuição todas as energias e capacidades naturais, de modo a adquirir os conhecimentos mediante um esforço próprio. Segundo este modo de entender o ensino, o nosso livro de leitura oferece bastantes motivos (...), para que o professor possa dar todas as lições, sugerir todas as noções $e$ desenvolver todos os exercícios escolares, para a boa instrução intelectual de seus alunos (...), de acordo com os programas atuais e com quaisquer outros que se organizem com a moderna orientação da Pedagogia (Grifo nosso. BOMFIM; BILAC, 1925, p. VII).
Percebe-se, isso a partir da última citação de Bilac e Bomfim, o significado da prática do professor na sala de aula, ou mesmo de sua fala, afinal a sua postura encarna uma posição oficial, ou ainda "a autonomia do leitor se submetia ao arbítrio do professor e à repetição do escrito" (BANDEIRA DE MELO, 2008, p. 69), afinal "é ele quem ensina". Tal perspectiva somada à unissonante presença do livro de leitura como único material escolar, como já mencionado, enfatiza a importância da maneira como os grupos étnicos brasileiros são representados e, por conseguinte, percebidos a partir desse tipo de literatura.

A trama se inicia narra a história de dois irmãos, Carlos e Alfredo, estudantes no Recife e que tinham apenas o pai, engenheiro de uma estrada de ferro, como família, naquele momento, além de parentes no sul do país. A estrada de ferro é uma informação importante no que diz respeito à evidenciação do que entendiam ser a "modernização" do país, como Varnhagen já havia apresentado no século anterior. Pode-se ainda entender as linhas férreas, apresentadas no decorrer da narrativa, como meio eficiente em que "o Estado tentava promover a integração de todas as regiões do território brasileiro" (CASTILHO, 2005, p. 4).

Os irmãos, ao receberem a notícia de que o pai estava doente em outra cidade, partem ao seu encontro, dando início a uma viagem através do Brasil. Os autores utilizam da curiosidade do personagem Alfredo, o mais novo dos irmãos, para apresentar informações a serem utilizadas em sala de aula. O emprego da curiosidade ingênua da criança é usado de maneira a causar uma experiência de aproximação e mesmo, por que não, identificação/empatia com o personagem, principalmente na ação do pequeno em indagar o motivo de ser das coisas que via. Prevalece no livro, então, a permanência de uma constante valorização da viagem e, consequentemente, do testemunho como 
vínculo privilegiado no que diz respeito à "realidade". A partir de um relato de viagem fictício, que é como os autores desenvolvem a narrativa, ressalta-se a necessidade de "deixar transparecer o modo como o adulto quer que a criança veja o mundo. (...) Dessa maneira, o escritor, invariavelmente um adulto, transmite a seu leitor um projeto para a realidade histórica, buscando a adesão afetiva e/ou intelectual daquele" (Grifo nosso. LAJOLO; ZILBERMAN, 2007, p. 19).

Considerando esta perspectiva de "projeto para a realidade histórica", o índio volta a aparecer na indagação do pequeno Alfredo, a partir da figura de Caramuru, que é apresentado e explicado por Carlos, o mais velho. A apresentação do Caramuru, a partir da obra de Santa Rita Durão, permeia duas propostas importantes para o período, a saber: 1) a importância da miscigenação entre indígenas, europeus e seus descendentes e; 2) mesmo a partir de uma hierarquização entre os povos, pode-se perceber certa “intimidade" entre as etnias apresentadas, e mesmo o estabelecimento de alianças. Essas alianças entre europeus e indígenas eram fundamentais para, além da sobrevivência do próprio europeu, desmistificar um determinado imaginário negativo do indígena, muito em voga na Europa até o século XVIII a partir de autores que "viram em geral mais os [seus] defeitos do que a virtude" (BARROS, 1973, p. 140). A miscigenação era compreendida como sendo fundamental à constituição da história e da nacionalidade brasileira que se formava, por mais que seja hierarquizada a partir do elemento étnico europeu. $\mathrm{Na}$ trama o final da história do Caramuru é apresentado a partir desta hierarquia na qual prevalece sutilmente o elemento europeu, pois mesmo que Diogo Alvares tenha vivido entre os indígenas e casado com uma mulher nativa, Paraguassú já estava batizada sob o nome cristão de Catarina (BOMFIM; BILAC, 1925, p.
34). Ou seja, em "Através", Bilac e Bomfim também apresentam a importância da miscigenação, o que pode ser encarado como positivação do indígena, muito presente entre os românticos do XIX. Porém, deve-se ressaltar o que essa presença de hierarquia entre os elementos indígena e branco produz a partir do tema "miscigenação": uma situação de tensão, que não negativa necessariamente o indígena, porém não apenas positiva.

Nesse sentido, uma passagem merece destaque no texto de Bilac e Bomfim, a partir da perspectiva de tensão entre a positivação do indígena e a negativação/ silenciamento, em "Através do Brasil", ocorre apenas uma rápida menção à antropofagia ocorrida em território brasileiro. A prática cosmo-ritualística de algumas etnias brasileiras é apresentada como uma experiência que não cabia mais em um mundo civilizado e, assim, havia sido deixada de lado há muito tempo. Assim como fez Varnhagen, a carga negativa sobre a antropofagia deixa de apontar para outras possibilidades de conteúdo simbólico sobre os grupos étnicos e ainda generaliza-os. Neste sentido é sintomática a apresentação do diálogo entre os irmãos:

[Carlos se dirige ao irmão] -Houve também um português, que naufragou mais para o sul, em 1512, em São Vicente, onde é hoje a cidade de Santos, no Estado de São Paulo. Também esse, que se chamava João Ramalho, escapou de ser devorado pelos índios, e chegou a domina-los [SIC.] de tal modo que com eles viveu até idade avançada, constituindo família e sendo encarregado mais tarde, por Martim Affonso, do governo da colônia ou vila militar de Piratininga, que foi a origem da atual cidade de São Paulo.

[Alfredo responde] - Mas parece impossivel que os índios pudessem comer carne humana! Que coisa horrivel, Carlos! (Grifo nosso. BOMFIM; BILAC, 1925, p.35). 
A passagem acima, embora demonstre a possibilidade de relação íntima com os indígenas, ou seja, a possibilidade de constituição de um povo miscigenado a partir da "constituição de família" pelos colonos, demonstra com destaque, o momento ápice na fala de Alfredo, em sua completa abnegação acerca do canibalismo. No entanto, é importante perceber um ponto fundamental: o irmão mais velho, após compreender a reação drástica do mais novo, destaca que "a vida dos selvagens era muito diferente da nossa, em tudo...”(BOMFIM; BILAC, 1925, p. 35). Nesse sentido, é importante ressaltar a tensão entre a negativação do indígena canibal, uma "coisa horrível", e a positivação a partir de sua própria historicidade, ou seja, "era muito diferente". Assim, por mais que possamos perceber nas falas dos irmãos uma presentificação brusca do passado isso a partir de "técnicas que produzem a sensação (ou melhor, a ilusão) de que os mundos do passado podem tornar-se de novo tangíveis" (GUMBRECHT, 2010, p. 123), o que deve ser destacado é a possibilidade de problematização desse passado, ou ainda, de entender os indígenas a partir de sua própria historicidade, evitando, assim, uma empatia excessiva, mas também uma negativação também exagerada, demonstrando uma constante tensão entre positivação e negativação, ou silenciamento.

Além da ideia "abominável" de ingestão de carne humana, os indígenas são mencionados ainda em um capítulo próprio, chamado "A Vida Selvagem". Carlos, após ser indagado pelo irmão mais novo, demonstra o quão "terríveis" eram as guerras, enfatizando o rancor entre os grupos étnicos. Esse rancor "só desapareceria quando uma delas [aldeias] era totalmente destruída pela outra" (BOMFIM; BILAC, 1925, p. 37), o que se aproxima bastante à proposta de Varnhagen de reduzir a sociabilidade indígena apenas aos conflitos sangrentos. Carlos ainda enfatiza que o destino dos prisioneiros desses conflitos era ou bem a escravização ou bem a antropofagia.

É neste mesmo capítulo, “A Vida Selvagem”, que os autores apresentam a primeira de duas referências aos indígenas do presente:

Algumas tribos odiavam-se tenazmente, com um rancor que só desaparecia quando uma delas era totalmente destruídas pela outra. Os prisioneiros eram comidos ou escravizados. As armas eram variadas.[...] Alfredo ouvia com grande atenção o que o irmão lhe dizia. Mas não the saía da cabeça, particularmente, a ideia horrivel dos banquetes de carne humana...

-Que barbaridade! E ainda há muitos indios no Brasil?

-Há alguns, no interior de Mato Grosso, de Goiás, Espirito Santo, São Paulo, Paraná, Santa Catarina, Maranhão, conservando a sua vida independente $e$ os seus costumes ferozes. Mas perto das povoações, já todos eles se vão à vida civilizada... (BOMFIM; BILAC, 1925, p. 38/39).

Mesmo que "ainda" houvesse "alguns" índios no Brasil, eles não fariam parte do corpo nacional brasileiro, afinal "conservavam a sua vida independente e os seus costumes ferozes", isso para os grupos bravios. Já os grupos "mansos", ou seja, os "civilizados", estariam mais próximos aos costumes e compreensões ditas civilizadas. A importância dessa passagem se torna clara: enquanto outros livros de leitura estipulam os indígenas apenas no passado, Bilac e Bomfim demonstram a permanência do indígena, mesmo que de forma hierarquizada. Em um momento em que o debate popular demonstrava a iminência do desaparecimento dos povos indígenas, os autores apontam para a sua permanência, o que pode ser encarado como um ponto muito positivante da figura indígena nos livros de leitura.

No $17^{\circ}$ capítulo, os irmãos e um companheiro de viagem, Juvêncio, encontram uma vila e, "naquele 
lugar, houvera uma aldeia de índios, de que ainda se viam vestígios" (BOMFIM; BILAC, 1925, p. 86). Aparentemente imperceptível essa passagem pontual demonstra o ainda importante objetivo "civilizatório". Onde havia uma aldeia de indígenas "selvagens", a civilização tomava lugar, o que demonstra, mais uma vez, a tensão entre a positivação do indígena e, nesse caso, o silenciamento da presença indígena no tempo dos autores. Tal conclusão coincide também com os objetivos iniciais do Serviço de Proteção ao Índio (SPI). O então chamado Serviço de Proteção aos Índios e Localização de Trabalhadores Nacionais (SPILTN) foi criado em 1910, mesmo ano da primeira publicação da obra. Tal órgão, na prática, promovia a utilização da mão de obra indígena, de modo que promoveria uma mínima aceitação dos grupos étnicos no corpo nacional, deixando seu suposto estado evolutivo inferior e abraçando a "civilidade"4 É importante ressaltar que os autores de Através não repercutem todos os argumentos desta compreensão e projeto, apesar de participarem deste espaço e de serem orientados por estes elementos, o que demonstra uma tensão constante entre a positivação dos indígenas e sua negativação. Bomfim, por exemplo, aponta que permaneceu na memória brasileira a...

(...) pouca importância que dão às populações naturais quanto à formação do Brasil. (...) Deste modo, os brasis [os indios]são apresentados no tipo de selvagens quase nulos; e o geral os julga na bitola dos miseráveis refratários à civilização, refugos, que subsistem nos sertões remotos. Nada mais falso, ou, pelo menos, mais incompleto. O indígena foi fator essencial na construção do Brasil (BOMFIM, 1929, p. 92/93).

Para Manoel Bomfim e Olavo Bilac, a escola primária deve ensinar muito mais do que aqui se convém, e muito mais do que se possa conter em qualquer livro de leitura. Quando a pedagogia recomenda que as classes primárias elementares não tenham outro livro além do de leitura, não quer dizer com isso que nesse livro único se incluam todas as noções e conhecimentos que a criança deve adquirir (BOMFIM; BILAC, 1925, p. V).

Os autores alertam assim para os limites que o livro continha, ficando claro o objetivo que ambos tinham para a construção do cidadão, educado pela disciplina de "Moral e Cívica", para uma nação que, como já mencionado, caminhava para o progresso. Tal progresso que, muitas vezes, não coincidia com a existência de indígenas no território brasileiro, como defendia Varnhagen no século anterior. Após as passagens mencionadas, o livro trata os indígenas com menos ênfase. São mencionados enquanto os irmãos passam pela costa do Rio de Janeiro, na utilização de palavras vinculadas à família linguística Tupi-Guarani, como "Guanabara" (Capítulo LXI, "A Capital Federal”, de "Através do Brasil"), e a partir da poesia de Gonçalves Dias (Capítulo LIX, "O Gigante de Pedra" de "Através do Brasil").

Os remanescentes indígenas, a partir da leitura de "Através", se encontrariam em um número maior apenas quando próximos ao rio Amazonas, como apresenta o capítulo "O Amazonas", segunda das duas menções aos grupos étnicos na República: “os índios daqui, - porque ainda se encontram muitos índios, quase todos já domesticados - os índios conhecem bem quando a terra começa a afrouxar, e embarcam logo, para não serem arrastados" (BOMFIM; BILAC, 1925, p. 306). Esta é uma passagem ambivalente e deve ser

\footnotetext{
${ }^{4}$ Destaque-se aqui o termo aceitação, pois não vemos a utilização desta mão de obra como participação no corpo nacional. Os indígenas não eram vistos como parte da sociedade, assim como não eram vistos claramente como cidadãos.
} 
lida com cuidado. Os autores apontam que os indígenas, em seu presente republicano, "ainda eram muitos", o que demonstra a preocupação, principalmente de Bomfim, com os autóctones contemporâneos. Esta é uma informação importante, pois, diferentemente de tantos outros autores, em "Através", aqueles indígenas tinham ao menos algum espaço na contemporaneidade. Em contrapartida, a passagem demonstra também o binômio civilização/ selvageria, a partir do ideal de "domesticação"dos indígenas, o que traz algo negativo, pois posiciona o indígena num espaço pouco relevante, mas, a um só tempo, diferente de Varnhagen, eles também aparecem como brasileiros, ou melhor, como parte de um corpo nacional. Ao mesmo tempo que isso aproxima os indígenas de uma certa "civilização", ou seja, que os aproxima ao corpo nacional, essa alternativa só existe a partir da "domesticação" de sua aculturação.

Aqui é necessário um esforço para entender a simplificação de algumas informações para materiais didáticos. Enquanto Manoel Bomfim criticava teorias evolucionistas aplicadas ao gênero humano 5 , "Através" produzia uma sensação diferente. Para Bomfim,

\begin{abstract}
nossas histórias correntes, falhas em tanta coisa, o são, principalmente, na pouca importância que dão às populações naturais quanto à formação do Brasil. Desvirtuados os fatos, exagerados uns tantos aspectos, ficaram, na mentalidade geral, os preconceitos pueris - de que os indígenas foram sempre cruelmente tratados, perseguidos, trucidados... e que, assim, se exterminaram as tribos (BOMFIM, 1929, p. 92).
\end{abstract}

É importante ressaltar que, para esse autor, ainda havia, sim, indígenas no Brasil, "mesmo que fosse no Amazonas", como mencionado na passagem anterior, no entanto, se o leitor não tivesse uma leitura cuidadosa, esta informação poderia passar despercebida. Percebe-se assim que "Através" apresenta uma simplificação, esvaziando o sentido que Bomfim promovia, a saber: os indígenas não pertenciam a uma escala evolutiva inferior ${ }^{6}$, mas sim a uma cultura diferente, que, vale ressaltar, e intensificando o movimento de tensão que temos tentado reconstituir, poderiam e mesmo foram, sim, compreendidas pelos autores como menos sofisticadas. O que parece estar em questão aqui é que se os indígenas, por um lado, seriam "menos sofisticados", por outro, não se trataria de uma simples superação de toda e qualquer determinação ou orientação em prol da cultura europeia. Muito pelo contrário, os autores, especialmente Bomfim, compreendiam que ambas as culturas - indígena e europeia - precisariam ser igualmente criticadas, pois eram dotadas de orientações positivas e negativas. No que tange ao presente trabalho, é importante salientar como tais informações teriam sido aproveitadas e utilizadas em ambiente escolar, construindo uma determinada memória sobre os grupos étnicos brasileiros.

As imagens, como já mencionado, representariam de forma verídica os indígenas. Em "Através", a temática indígena se destaca em quatro imagens distintas. Assim,

o escritor, assim como um artista ao pintar um quadro, ao filtrar o mundo e focar o olhar do leitor e do contemplador de arte de determinada forma, reflete o saber de uma época através do fio condutor desse olhar, que o levou a representar o indivíduo de uma

\footnotetext{
${ }^{5}$ Pode-se perceber esta crítica de Bomfim em várias obras, como em "O Brasil na História”. Para leitura sobre o tema, consultar FERREIRA; RANGEL, 2014. ${ }^{6} \mathrm{O}$ darwinismo social é uma proposta teórica que ganhou força no final do século XIX, principalmente no Reino Unido e América do norte. Era proposto uma adaptação das teorias evolucionistas de Darwin às sociedades humanas, principalmente a respeito da sobrevivência do mais apto. Para leitura aprofundada, consultar MERCIER, 1974.
} 
forma peculiar correspondente a sua visão e a sua concepção de valores (CASTILHO, 2005, p. 6).

É importante lembrar que era intenção dos autores apresentar "a realidade" e, por isso, preferiram "ilustrar este livro somente com fotografias" (BOMFIM; BILAC, 1925, p. VIII-IX). As imagens, como os autores apontaram em "Advertência e Explicação", seriam imagens verídicas. Assim, três das quatro imagens sobre indígenas corroborariam tal proposta (Anexo I).

Podemos dizer que, a partir do sentido de veracidade explicitado pelos autores, a imagem do indígena, transmitida em "Através do Brasil”, pretende liberar elementos para a constituição da imaginação do aluno, de forma que "pinturas, estátuas, publicações e assim por diante permitem a nós [na] posteridade, compartilhar as experiência não-verbais ou o conhecimento de culturas passadas (...) Em resumo, imagens nos permitem 'imaginar' o passado de forma mais vívida" (PALHARES, 2012, p. 25). As imagens têm uma aproximação maior com ilustrações enciclopédicas, embora os autores tenham tentado desvincular sua obra dessa citada categoria.

As três gravuras em anexo, baseadas em fotografias, ou seja, contemporâneas a Bomfim e Bilac, apresentam imagens estáticas, posadas, próximas a algumas obras realizadas por Rugendas ou mesmo por Von Spix e Von Martius, ao divulgar por desenhos os achados de suas viagens (Anexo II). Isto reforça uma conotação científica ou, no mínimo, baseada em pesquisas. Ao mesmo tempo em que aproximam a obra de um espaço cientificista também produzem a estabilização de seu conteúdo ou mesmo o engessamento dos indígenas em um tempo, quase tornando-os objetos de museu, como é demonstrado nas imagens do Anexo II. Por fim, nenhuma das imagens oferece o indígena além do que se pensava ser seu meio "natural", as matas. No entanto, a quarta imagem difere das demais.

Pode-se perceber que a quarta imagem reproduzida sob a legenda "Taba índia" (Anexo III) difere em muito de outras imagens no decorrer do livro, pois na ilustração despontam quatro crânios humanos na entrada da aldeia, semelhante às ilustrações de "Duas Viagens ao Brasil" (1557), de Hans Staden. Essa imagem poderia oferecer uma interpretação negativa, associando novamente indígenas ao canibalismo. Ressalta-se que essa última gravura também estava cunhada como "verídica", pois os autores salientam que todas as imagens do livro eram baseadas "somente em fotografias". O que se destaca é a semelhança com a ilustração presente na obra de Hans Staden (Anexo IV).

Embora tenha sido traduzida para o português apenas no início do século XX, "Duas Viagens ao Brasil” teve grande influência na divulgação generalizada do indígena brasileiro como canibal. Não discutiremos a veracidade ou não da imagem veiculada a Staden, no entanto é curiosa a proximidade entre as duas imagens - a de "Através do Brasil" e a de "Duas Viagens ao Brasil" - e a carga simbólica que ela traz ao ambiente escolar e, consequentemente, à construção de uma determinada memória negativa sobre o indígena brasileiro.

A importância da vinculação de imagens no material escolar se destaca no auxílio da imaginação do aluno. Ainda, podemos dizer que era necessário

fazer com que os alunos aprendessem também 'pelos olhos', como sugeria Jonathas Serrano no início do século XX, espelhando-se no Francês Ernest Lavisse, que insistia na necessidade de fazer com que as crianças vissem cenas 
históricas, para compreender a história (LIMA E FONSECA, 2001, p. 92).

Para finalizar, é importante destacar a presença de um "Glossário" ao final da obra. Este capítulo apresenta palavras cujo significado o aluno poderia desconhecer. Assim, nas palavras dos autores:

Juntamos ao volume um pequeno léxico, em que damos a significação de alguns termos empregados, dos menos familiares às crianças. Em geral, procuramos das a estas páginas o tom singelo e a linguagem natural que mais convém à inteligência infantil; é este um dever rigoroso em trabalho desta natureza; mas seria impossivel evitar sempre o emprego de uma ou outra palavra menos trivial. Nem tanto se exige dos livros didáticos; se, em suas leituras escolares, a criança somente encontrar palavras muito conhecidas, como poderá ela desenvolver o seu vocabulário? (BOMFIM; BILAC, 1925, p. XII).

Como os próprios autores descrevem, é um "dever rigoroso" apresentar o significado das palavras ao aluno. Assim, alguns dos termos se destacam no que tange a temática indígena, a saber: 1) antropófago; 2) bravio; 3)Tapuio e 4) tribo. Embora o conceito "antropófago" esteja coerente com a definição denotativa do dicionário Antônio de Moraes Silva ${ }^{7}$, "Tapuio" é definida da seguinte forma: "nome genérico dos índios do Brasil" (BOMFIM; BILAC, 1925, p. XI do "Glossário"). Os autores apontam como a nomenclatura dos grupos étnicos era feita de forma superficial, "genérica", denunciando a falta de divulgação dessa informação, o que incentivava a permanência da generalização e discriminação, e também a falta mesmo de conhecimento das múltiplas sociedades indígenas que existiram no passado e existiam na República. A denúncia desta generalização pode ser vista de maneira positiva e muito próxima da acusação realizada por Gonçalves de Magalhães a Varnhagen, ainda no século XIX. Bilac e Bomfim possibilitam, então, uma alternativa à propensão da estereotipação do Outro e também à "uma renúncia da própria memória viva, coletiva, afetiva e espontânea dessas crianças, que deveriam substituí-la pela memória histórica deuma nação sacralizada e idealizada, com heroico passado e promissor futuro" (CORDEIRO, 2005, p. 66).

Em contrapartida, a palavra "tribo", que já apresenta forte relação com as perspectivas evolucionistas, é definida por "aglomeração de famílias ou povos" (BOMFIM; BILAC, 1925, p. XI do "Glossário"). Dessa forma, e também a partir do dicionário Moraes Silva, "aglomerar" é definido por "amontoar, reunir como um novelo" (MORAES SILVA, 1890, p. 107), excluindo a organização social presente nos grupos étnicos. Portanto, essa definição encontrada no dicionário "Moraes Silva" possui uma carga semântica negativa, muito próxima à perspectiva de Varnhagen sobre os indígenas: para o historiador, os indígenas se encontravam em situação social desorganizada, ou seja "aglomerada", distante do que se entendia por "civilização".

A palavra "bravio" traz uma carga específica às definições apresentadas aos alunos. Definida no livro de leitura apenas como "selvagem", a palavra traz duas possibilidades denotativas, a saber: "homem silvestre, nascido e habitante das selvas, matos; [ou] bruto, irracional, feroz" (MORAES SILVA,1831, p. 706). Desta forma o índio bravio, em oposição ao índio manso/civilizado, poderia ser definido para os alunos 
como quem vive nas selvas ou como irracional/feroz, o que reifica aquele imaginário que ganhou força com as propostas de Varnhagen e também permanecia na Primeira República. Para fechar o raciocínio, é importante mencionar mais um significado contido no "Glossário": "inóspito" é definido como "selvagem, impróprio para a vida humana" (BOMFIM; BILAC, 1925, p. VII do "Glossário"), apresentando os termos como sinônimos.

\section{Considerações finais}

A sensação que "Através do Brasil" passa aos alunos é de tensão, ora positivando e ora negativando os indígenas, ou silenciando-os. A leitura passa também a sensação de integração nacional. A unidade nacional do século XIX, de acordo com certa interpretação proposta por Von Martius e “... enfatizando a mescla de raças que marcava o país, porém, valorizando a 'raça' branca na constituição do povo brasileiro" (GROENENDAL; BRASIL, 2009, p. 3) foi um direcionamento realizado nas escolas, a partir desta tensão que procuramos demonstrar produzindo uma determinada memória escolar. Tal memória é reforçada pela utilização de apenas um material escolar defendida pelos autores:

Deste modo, sob sugestão das mesmas páginas, todo o programa pode ser ensinado. Qual a vantagem? É que todo $o$ ensino fica assim harmonizado, como irradiação ou desenvolvimento de uma só leitura; e essa leitura é bastante, a todo o momento, para evocar os conhecimentos adquiridos, que dessa forma se assimilam muito mais fácil e naturalmente. (BOMFIM; BILAC, 1925, p. XI)

Como demonstra Circe Bittencourt, "o ensino de 'humanidades' inseria-se na formação dos futuros dirigentes da nação brasileira" (BITTENCOURT, 1990, p. 61), de forma que tanto a possibilidade sobre a positivação do indígena brasileiro era possível quanto a possibilidade de negação e produção de uma "invisibilidade" significativa em relação aos autóctones, frente à demanda de modernização e progresso do país. Assim, o material escolar, que diz respeito aos livros de leitura, livros didáticos, manuais escolares, etc., são importantes fontes e se colocam em um lugar específico no "amplo processo histórico e cultural da escolarização" (GASPARELLO, 2004, p. 20), que por sua vez influencia na memória coletiva de parte considerável da sociedade brasileira. 


\section{Referências}

AGUIAR, Ronaldo Conde. O Rebelde Esquecido: tempo vida e obra de Manoel

Bomfim. Rio de Janeiro: Topbooks, 2000.

ALMEIDA, Juniele Rabêlo e ROVAI, Marta Gouveia de Oliveira. Introdução à

História Pública. São Paulo: Editora Letra e Voz, 2011.

ALVES, Gilberto. Manuais Didáticos de História do Brasil no Colégio Pedro II: do Império às primeiras décadas da República. Revista HISTEDBR On-line, Campinas, nº 5, Set. 2009.

BANDEIRA DE MELO, Ciro Flávio de Castro. Senhores da História e do Esquecimento: a construção do Brasil em dois manuais didáticos de História na segunda metade do século XIX, Belo Horizonte, MG: Argvmentvm, 2008.

BARROS, Roque Spencer Maciel de. A Significação Educativa do Romantismo Brasileiro: Gonçalves de Magalhães. São Paulo, EDUSP, 1973.

BASTOS, Alcmeno. Alencar e o índio do seu tempo. Revista o eixo e a roda. v. 21, n. 2, 2012.

BASTOS, Maria Helena. Cuore, de Edmundo de Amicis: sucesso Editorial, 2004. Disponível em: <http:// www.intercom.org.br/papers/nacionais/2004/resumos/R0767-1 . Acesso em 26/04/2017>.

BITTENCOURT, Circe Maria. Pátria, Civilização e Trabalho. Edições Loyola, 1990.

BOMFIM, Manoel. O Brasil na América: caracterização da formação brasileira. Rio de Janeiro, Livraria Francisco Alves, 1929.

BOMFIM, Manoel; BILAC, Olavo. Através do Brasil. Rio de Janeiro: Francisco Alves, 1925.

CASTILHO, Mariana Moreno. A configuração da imagem do indígena por Olavo Bilac

e Manoel Bomfim na obra Através do Brasil. Anais da ANPUH - XXIII Simpósio nacional de história Londrina, 2005.

CORDEIRO, Andreia. Dando Vida a uma Raiz: o ideário pedagógico da Primeira República na poesia de Olavo Bilac. Dissertação (mestrado) UFPR, 2005.

FERREIRA, Clayton J. História na Primeira República: perspectivas ético-políticas nos ensaios de Paulo Prado e Manoel Bomfim. Dissertação (mestrado) UFOP, 2016.

LIMA E FONSECA, Thais Nívea de. "Ver para compreender”: arte, livro didático e a história da nação. In: SIMAN, Lana Mara de Castro (Org.). Inaugurando a história e construindo a nação: discursos e imagens no ensino de história. Belo Horizonte: Autêntica, 2001.

FRADE, Isabel C. A. S.; MACIEL, Francisca I. P. (orgs.). História da Alfabetização: produção, difusão e circulação de livros (MG / RS / MT-Séc. XIX e XX). Belo Horizonte: Sografe, 2006.

GASPARELLO, Arlette Medeiros. Construtores de Identidades: a pedagogia da nação nos livros didáticos da escola secundária brasileira. Editora IGLU, 2004.

GROENENDAL, Patrícia \&BRASIL, Maria do Carmo. As Representações do

Brasileiro em Tempos Diversos. Anaisda ANPUH - XXV Simpósio nacional de história - Fortaleza, 2009.

GUMBRECHT, Hans Ulrich. Produção de Presença: o que o sentido não consegue transmitir. Ed. PUC-RIO, 2010 .

HALBWACHS, M. A memória coletiva. São Paulo: Vertice, 1990.

HANSEN, Patrícia. Os primeiros livros infantis brasileiros: análise da literatura cívico-pedagógica de ficção. Riode Janeiro: Programa Nacional de Apoio à Pesquisa da Biblioteca Nacional, 2010.

LAJOLO, Marisa. Usos e abusos da literatura na Escola: Bilac e a literatura escolar na 
República Velha.Rio de Janeiro: Editora Globo, 1982.

MERCIER, Paul. História da Antropologia. Editora Eldorado, 1974.

MONTEIRO, John M. Tupis, Tapuias e Historiadores: estudos de história indígena e indigenismo. Tese (Livre Docência) UNICAMP, 2001.

MORAES SILVA, Antônio. "Dicionário da Língua Portuguesa” - volume I, 1890

. "Dicionário da Língua Portuguesa" - volume II, 1831.

PALHARES, Leonardo Machado. Entre o verdadeiro histórico e a imaginação criadora: Ilustrações sobre história e cultura dos povos indígenas em livros didáticos de História. Dissertação (mestrado) UFMG, 2012.

PEREIRA, Maria José de Araújo \& GONÇALVES, Renata. Afetividade: caminho para

aprendizagem. Revista Alcance, v. 1, n. 1, 2010.

PINHEIRO, Alexandra e MOREIRA, Kênia. Livros de leitura na primeira metade do

século XX: concepções de leitura e de leitores. 2011. Disponível em: <www.unigran.br\%2Finterletras\% 2Fed_anteriores\%2Fn12\%2FLIVROSDELEITURANAPRIMEIRAMETADODOSECULOXX.doc73>.

Submissão: 26/04/2017

Aceite: 01/09/2017 